Ekonomia - Wroclaw Economic Review 24/3 (2018)

Acta Universitatis Wratislaviensis

No 3881

DOI: 10.19195/2084-4093.24.3.7

Karolina Kulińska

ORCID: 0000-0002-0143-8368

Uniwersytet Wrocławski

karolina.kulinska@uwr.edu.pl

\title{
Legal and practical aspects of access to health care for people with hearing loss in selected European countries
}

Date of submission: 1 June 2018; date of acceptance: 10 September 2018

JEL Classification: H51, H75, I11, I14, K23

Keywords: hearing loss, sign language, healthcare, sign language interpreter, medical interpreting

\begin{abstract}
Legal and practical aspects of access to health care for persons with hearing loss in selected European countries
\end{abstract}

The article presents the outcomes of legal research combined with quantitative and qualitative research review concerning access to health care for people with hearing loss in selected European countries: United Kingdom, Federal Republic of Germany and Republic of Poland. The main objective was to verify if and how this issue, especially communication and access to information, is solved in different legal systems. Secondly, by comparing the established legal framework in each country with available data on actual quality of healthcare provision, it was assessed whether any regularities between the chosen models of regulating rights of people with hearing loss and real-life adjustments for those patients can be detected. The objective scope of the research includes any type of hearing loss which affects spoken language communication, that is not only $\mathrm{d} /$ Deaf but also deafblind and hard of hearing persons, if only their primary and/or preferred way of communication is the not-spoken one. The main findings of the performed analysis are that key sources of barriers in access to healthcare are the lack of awareness on the side of both patients (regarding their rights) and healthcare providers (specificity of hearing impairments) and the fact that enhancements in the professional status of sign language interpreters and other communication assistants are needed. 


\section{Introduction}

Communication in the medical staff-patient relationship is a link connecting a sequence of actions undertaken in at least three areas: the treatment process, the process of implementing the state health policy and the actions taken to protect patient rights. This is illustrated well by the example of the obligation to provide the patient with information about his or her health. Compliance with this obligation does not only affect further treatment (proper dosage of drugs, avoidance of harmful activities), but also shapes certain attitudes (by encouraging preventive actions) and corresponds with the patient's right to receive such information. In literature, theoretical models of the doctor's interaction with the patient are constructed in order to optimize the above processes and in the broad perspective - to increase the efficiency of healthcare provision. The starting point for research in this area is to identify the participants of the discourse. Usually, during medical examination the information flows directly between two entities: a patient and a medical service provider. Only as a result of their communication or upon the patient's consent a third party may be involved in the interaction. In the case of certain groups of patients, however, a third party must always be included, which applies in particular to minors, people with limited mental capacity and foreign language speakers.

Contrary to the common approach, the latter category includes not only foreigners but also, or maybe even especially, people with hearing and/or speech impairments who do not use spoken languages as their first language. Those patients face a communication barrier in the strict sense. Patients such as minors or people with mental disabilities lack the ability to fully understand risks concerning their health and therefore to make their own decisions in that regard. A third person such as a parent or legal guardian performs the role of not so much (or at least not just) an intermediary but more of a co-participant who actively protects the patient's interests. Quite the opposite is the case with foreigners or people with hearing loss, who are independent administrators of their health situation and all related information. They are able to share it and receive it but in a language incomprehensible to the doctor and vice versa. Consequently, mutual understanding may be reached only with the help of an interpreter or with the use of other communications aids.

If an interpreter is involved in the act of communication, where he or she is the only one who understands both languages, he or she becomes the guarantor of the correct flow of information between the participants of the discourse. Interpreting is always burdened with the risk of distorting the output message. In the context of the provision of medical assistance, errors in interpretation or translation may result in further, extremely significant risks including the threat to the patient's life and health. Therefore, the interpreter should be characterized by professionalism, reliability, fluent knowledge of medical vocabulary in both languages and he or she should be able to certify his or her competences. 
This postulated set of features is gaining importance when a patient is a person who is not a native spoken language user, also in writing. Unlike foreigners who, except in emergency circumstances, use a medical service provided in a foreign language as a result of their choices, such as moving to another country or deciding to travel, people with hearing loss must face such situations everywhere for the entirety of their lives. The potential share of foreign-language patients in a given healthcare area is difficult to predict, especially within the Schengen area. It is not only about the statistical number of such patients in the individual regions, but also their language competences must be known, and these are not automatically linked to one's nationality.

For most of the people with hearing loss, any spoken language will always be the second one. People with hearing loss are full-fledged citizens of a given country, which due to congenital or acquired traits are unable to use the official spoken language of a given country as a native language. As a rule, this feature is constant and the number of not-spoken- language users in a given country is measurable. Their contacts with the health service are not incidental, they need some form of communication mediation aids throughout their lives. Therefore, access to communication aids for those patients should always be guaranteed and protected by law.

The category of "people with hearing loss" is not homogeneous. The term itself is rather a simplification and it will be used for the purpose of this article to cover all people who, due to congenital or acquired, permanent or transient hearing organ dysfunctions and/or the accompanying dysfunctions of other organs, experience a permanent or temporary difficulty in communicating using speech and/or writing. Consequently, the term applies to deaf people (complete hearing loss), as well as people who are hard of hearing or deafblind. Depending on the moment of the appearance of hearing loss, prelingual, perilingual and postlingual hearing loss can also be distinguished (Krakowiak 2006). Postlingual hearing loss refers to people who have learned speech before hearing loss and who are able to use it. Prelingual hearing loss concerns children who were already born with damaged hearing organs or have lost the ability to hear by the first year of life, that is at a time when they have not mastered the main "auditory functions" yet. Perilingual early hearing loss concerns children who have lost the ability to have hearing after developing "hearing functions", but before they have mastered a "language system" (2-3 years old). Late perilingual hearing loss refers to children who have lost their hearing when they had already learned the language, but before the phonological system has been completed and before speech was fully developed.

Prelingual and perilingual hearing impairments result in difficulties and disorders in spoken language communication and also disturb its development. The shortage of verbal communication with the environment results in a decrease in the number of language experiences and makes it harder or even impossible to identify a (spoken) "language system". In other words, not every person with hearing loss 
understands spoken languages (also in writing), but also not every person with hearing loss is a native sign language user.

People who speak spoken languages fluently (mostly persons with postlingual hearing loss and minor speech or hearing impairments) and are able and willing to use it, especially in writing, de facto do not experience barriers in communicating. The problem of access to healthcare as a result of the communication barriers pertains mainly to the people with hearing loss who are able to precisely and fully understand information only in sign language or using another unspoken way of communication. The main research problem in the article is, therefore, to examine in a comprehensive manner if and how those special communication conditions in relation to patients with hearing loss affect their access to healthcare in practice and whether those conditions are envisaged in legal systems in selected European countries.

\section{The theoretical aspects of research}

The access of people with hearing loss to healthcare is the subject of research all over the world, including Republic of South Africa, Brazil or Ghana (Chininthorn, Glaser, Tucker, Diehl 2016; Chaveiro, Porto, Barbosa 2009; Appiah, Fenu, Asalu, Dzata, Bonchel, Abdul-Rahman, Dongdem 2018). Problems experienced by patients with hearing loss in communication and the prevalance of health literacy among them was also the subject of systemic and narrative reviews. A survey by Naseribooriabadi, Sadoughi, Sheikhtaheri showed that limited health literacy among deaf people which also leads to a poorer health status, could be improved by "four 'facilitators' composed to the following four sub-themes including protecting deaf people right to access to health services, providing sign language interpreter, training health providers about deaf culture, and developing deaftailored programs in health education" (2017, p. 1470). A theoretical review by Kuenburg, Fellinger, and Fellinger (2016, p. 2) also allowed to categorize the key challenges in the way of gaining adequate healthcare for deaf and hard of hearing people, that is communication challenges, lacking health knowledge and being at risk of marginalization. In that paper Krenborg et al. (2016, pp. 4-6) also provided ideas of how to improve access to medical treatment, such as:

- attention to the communication preferences of deaf people;

- provision of sign language interpretation in a medical setting;

- use and development of communication technology;

- cultural competency training for medical staff.

In other words, we could say that the focal points in improving a patient's with hearing loss access to quality healthcare are:

1. Knowledge - understood as both patient general health awareness gained thanks to appropriate educational resources, and medical staff realization of specificity of interaction with a hearing loss person acquired through dedicated training. 
2. Interpreting - including access to a professional (or at least trained) sign language interpreter or artificial communication means, such as various types of communication technology.

Both of those areas were explored in Medisigns, a Leonardo da Vinci-funded European Union project. The project carried out by Interesource Group Ireland Ltd. aimed to enhance the language skills of deaf people, interpreters, and healthcare professionals. As authors of the project observed (Nilsson, Turner, Sheikh, Dean 2013), there is a need for training materials and Continuous Professional Development courses for interpreters practising in the healthcare context, as well as for deaf people and medical staff. They also stressed the importance of triangular cooperation between patients, interpreters and healthcare providers since the burden of responsibility for the quality of communication must not be solely on the interpreter. Medisigns reported and analyzed data from five different EU countries: Poland, Ireland, Cyprus, Sweden, and the United Kingdom. Some of the major outputs of the project were: launching an AppStore application (available in Swedish), designing courses and materials related to medical sign language interpreting and issuing a European report on deaf healthcare provision (Nilsson et al. 2013).

However, although the report (Nilson et al. 2013, pp. 12-14) includes an overview of the legal setting of sign language interpreting in each of the examined countries, a lot more attention was paid to the bottom-up educational and organization aspects of the problem. At the same time, it was observed that one of the greatest obstacles in quality interpreting provision, apart from education, is the actual lack of sign language interpreters. The question arises, if the latter could be related to the law (or the lack thereof) sufficiently securing their position (through, for example, a professional title, guaranteed income tariff, reimbursement of costs, etc.). This can be verified by a comparative legal analysis.

Further, a relation between legislation in a given country and practical aspects of healthcare provision with the interpreter's assistance or use of other communication aids shall be examined, to assess if there is a causal link between law and quality of access to healthcare. If so, conclusions derived from such research would be valuable for future law-making initiatives on the supranational level by the EU legislator or by domestic law-givers, aiming to improve the situation of citizens with hearing loss.

\section{Methodology}

The article is comprised of comparative legal research and a qualitative research review. Each was carried out for three European Union Member States: Federal Republic of Germany, United Kingdom and Republic of Poland. Additionally, as EU legislation is a common legal denominator for each of the Member States, the EU legal framework for the protection of the rights of people with hearing loss and their access to healthcare was presented in a separate section. The choice of 
countries for the study was based on the three models of sign language interpretation regulation that one can observe in each of them:

- No statuary recognition of sign language, very general legal provision addressing the right to a sign language interpreter in a medical context (UK);

- Statuary recognition of sign language as a natural language, freedom of choice of the preferred form of communication in the medical context given by a statute, lack of delegated legislation related to organizational aspects of executing this right (Poland);

- Statuary recognition of sign language as a natural language strengthened by granting it a status equal to the "official" language, the right to sign language interpreting given by a statute secured by laws regulating the organizational aspect of interpretation provision (Germany).

As far as the quality research review is concerned, the aim was to collect the most current data, without compromising its exhaustiveness and reliability. For this purpose, reports and publications were collected from among others Medisigns (Poland, and the United Kingdom), European Union of the Deaf (EUD) (Germany, Poland, and United Kingdom), materials prepared by National Associations of the Deaf in each country were searched (with satisfactory results for the United Kingdom) and among other sources the Report on the implementation of the Convention on Rights of Persons with Disabilities in Relation to Persons with Hearing Disabilities (Poland) (Nowacka 2016, pp. 4-32) and research carried out in Johannes Gutenberg-Universität Mainz (Germany) (Höcker 2010). Research materials were analysed in their original versions (English, German and Polish respectively) and all translations cited here are self-provided.

\section{Access for people with hearing loss to healthcare in the European Union: The supranational dimension}

Healthcare provision is principally, yet not exclusively, a Member State's competence. Treaty on the Functioning of the European Union provides EU with shared competences in common safety concerns in public health matters and supporting competence in the protection and improvement of human health, along with the right and obligation to follow EU public health policy (Article 168). However, equal access to health care is a resultant of not only protection of human health but also of the aim to combat discrimination on the basis of disability or language and ensure integration of persons with disabilities, guaranteed in primary law of the EU. Those issues are further addressed in the Council Directive 2000/78/EC of 27 November 2000, establishing a general framework for equal treatment in employment and occupation, according to which the "principle of equal treatment" means that there is to be no direct or indirect discrimination on 
the grounds of disability. The directive also recommends reasonable accommodations for disabled people. An analogical instrument was proposed to combat discrimination outside the employment area in 2008, namely the Directive on implementing the principle of equal treatment between persons irrespective of religion or belief, disability, age or sexual orientation, which would prohibit discrimination based on religion in healthcare, however, legislative works are still in progress, and the directive remains only a proposal (European Commission 2008).

Simultaneously to actions within the health and anti-discrimination policy of the EU, the recognition of national sign languages is of a great importance, as rightly observed by Nina Timmermans:

Recognition of sign language as the preferred language of the deaf community is the first required step towards integration and full citizenship. The next step is the amendment of existing laws or the proposal of new laws in order to implement the political commitment in legislation and policies. Recognition should therefore be followed up by corresponding rights for the users of sign language, i.e. the right to free choice between oral or bilingual school systems, the introduction of sign languages as a communication channel in general and vocational education, and the adoption of practical measures for ensuring full participation by the minority of deaf people in the community. This will make it possible to achieve an increase in the number of interpreters and ease of access to public and private services, education, recreation and social activity, thereby making for significant enhancement of the quality of life and human rights for the deaf. (Timmermans 2003, p. 3)

European Union is a party to the United Nations Convention on the Rights of Persons with Disabilities (UNCRPD) and in 2011 it ratified it as a whole, however, without adopting the Optional Protocol. The Convention is recognized as the first international human rights instrument in the 21 st century and continues to have a great impact on the perception of disability from the legal perspective, stressing the social rather than the traditional medical dimension of the problem, which is emphasized in the introduced definition of persons with disabilities as including "those who have long-term physical, mental, intellectual or sensory impairments which in interaction with various barriers may hinder their full and effective participation in society on an equal basis with others" (UNCRPD, Article 1). Moreover, the Convention states that "language includes spoken and signed languages and other forms of non-spoken languages" (UNCRPD, Article 2). It is worth stressing that the wording of this definition provides a recognition of language rights of deafblind persons as well. State parties are to take appropriate measures in order to enable persons with disabilities, including persons with hearing loss "to live independently and participate fully in all aspects of life such as the provision of sign language interpreters" (Wheatley, Pabsch 2012, p. 30). Access to health services is to be ensured without discrimination on the basis of disability (UNCRPD, Article 25). An instrument to ensure the implementation of the obligations stemming from the Convention, especially Article 9, is the so-called European Accessibility Act. However, it is rather internal-market oriented, focusing on the access to goods and services for persons with disabilities (European Commission 2015). 
On the regional level, numerous actions were taken in relation to the issue of sign languages recognition 20 years before the Convention was even created, all of them so far introduced in soft law instruments. The first being the Resolution on Sign Languages for the Deaf of 1988 followed by the version of 1998, calling on the Commission, among others, to make a proposal to the Council concerning official recognition of the sign language used by deaf people in each Member State. In 2010 the Brussels Declaration on Sign Languages in the European Union called upon the EU and its Member States to also take all legal measures necessary to secure sign language users access to employment, education and public services in their national sign language. This document was drawn up by the European Union of the Deaf and later invoked in the so-called Mobility Report prepared by Adam Kosa, the first Deaf Member of the European Parliament. Again, it was calling for recognition of national sign languages, access to information and sign language services. The report is an example of initiatives undertaken as part of the European Disability Strategy 2010-2020: A Renewed Commitment to a Barrier-Free Europe.

Moreover, a specific type of healthcare services was addressed by the EU Parliament, namely emergency services. This issue shows the complexity of the analyzed subject matter, since by its very nature having an interpreter assisting during an emergency is very unlikely. In the Written declaration on the need for accessible 112 emergency services, the European Parliament called on the Commission "to put forward legislative and standardization proposals to make 112 services fully accessible to all citizens, giving priority to sign language services using video technologies and text-based services to ensure the inclusion of deaf, hardof-hearing and speech-disabled users" (European Parliament 2011). Ultimately, in the Resolution of 23 November 2016 on sign languages and professional sign language interpreters it was noted that although health care is a Member State competence, "it should cater for the needs of deaf, deafblind and hard-of-hearing patients, for example by providing professional sign language interpreters and staff awareness training, with particular attention to women and children" (European Parliament 2016).

The estimated number of deaf sign language users in the European Union for 2012 is 802,324 (Wheatley, Pabsch 2012, p. 22). Surprisingly, the estimated population of deafblind people is much higher - 2,734,721 (European Deafblind Network, 2014). Both figures become less indicative when compiled with the data on the official website of the European Federation of Hard of Hearing People, according to which there are currently 52 million people with a hearing loss ranging from a mild hearing loss to profoundly deafened adult users, each being a potential sign language user. Adding up the different ways and ranges of each national sign language recognition, it is profoundly complicated to come up with a one-fits-all communication right, especially seeing as the language policy of each Member State is their exclusive competence. Nonetheless, with regard to the 
access to EU institutions it was advised on page 98 of the Report on Implementation of the European Disability Strategy from 30 November 2017 "to give priority to interpretation from and into national sign language(s) rather than International Sign, in line with the EU's multilingualism policy".

\subsection{United Kingdom}

There are two national sign languages in the United Kingdom: British Sign Language (BSL) and Irish Sign Language (ISL). The latter is used both in Northern Ireland and the Republic of Ireland. According to a survey by Parks and Parks, ISL is mostly found in those areas of Northern Ireland with stronger Catholic ties, where students may have previously attended Catholic deaf schools in Dublin (2012, p. 9). The first linguistic research on BSL began in the mid-1970s (Deuchar 2013, p. 6). Apart from the languages, there can be distinguished mediate or mixed forms of communication, namely Sign Supported English (SSE), which could be described as "manually coded English". It is an artificial communication system, not a natural language; it uses visual signs but English grammar. The simultaneous existence of sign language(s) and sign supported systems is a common phenomenon, as the latter is useful for educational purposes and easier and quicker to learn by hearing persons, even encouraging them to learn signs. It has a subsidiary character, seeing as there are no native SSE users. Some deafblind persons may also use a deafblind manual which is a form of signing but including manual contact (it all depends on the magnitude of hearing and/or sight impairment).

In the United Kingdom, the Department of Work and Pensions recognized BSL in 2003, under the influence of bottom-up initiatives by deaf community activists. In 2004, both the BSL and ISL were recognized as languages in their own right in Northern Ireland. Both statements, however, were informal and more political in value. English itself is the de facto and not de iure official language of the United Kingdom. On the other hand, it is argued that the spoken minority languages of UK (Welsh, Scots, Ulster Scots, Scottish, Irish Gaelic and Cornish) are under protection, with Gaelic and Welsh being regulated in separate Acts and Welsh having additionally equal basis with English in public life. Advocacy for regulating the sign language users' situation as a linguistic minority rather than a type of persons with disability is common and it is also deeply rooted in the cultural identity aspect of deaf rights. The bottom line is that the access to BSL and ISL communication would be more effective if supported by legislation. As the British Deaf Association Northern Ireland reports, the current state leads to the unfair and unjust situation where in the Emergency Departments information in minority spoken languages is available, but to sign language users it is not $(2016$, p. 7$)$.

It does not mean that there is no legal obligation to deliver appropriate communication facilities. It is, however, quite generic in nature. For now, the legal act primarily addressing the situation of people with hearing loss is the Equality 
Act 2010, which provides a duty to make "reasonable adjustments" for people with disability to avoid disadvantage, and states that auxiliary aids for people with disabilities must be provided when the person is put at a "substantial disadvantage". Sign language interpreters are considered as auxiliary aids since they provide access to communication and information needed for appointments with general practitioners, in hospitals and in urgent care centres (Nilsson et al. 2013). Depending on the need, auxiliary aids could be SSE interpreting, text materials, video-interpreting or other means of communication technology. The legal norm is general and can be adapted to particular circumstances.

However, there is also no hierarchy of communication resources and no official guidance on how to organize an interpreter. According to research within the Medisigns project (Nilsson et al. 2013), healthcare providers either employ full-time staff interpreters or hire them ad hoc through a variety of interpreter referral agencies in the UK, including through many spoken languages interpreting agencies. The effectiveness of such cooperation depends strongly on the actual availability of interpreters. The easiest way to measure it is by checking the number of registered sign language interpreters. To join the National Registers of Communication Professionals working with Deaf and Deafblind People (NRCPD) in the UK as a registered sign language interpreter, one must be highly skilled in a signed language, such as BSL, ISL or American Sign Language, and the second language can be another signed language or a spoken language, one of which must be native to the UK and Ireland and the interpreter must complete one of the approved courses (NRCPD, 2018). To become a registered interpreter for deafblind people, the completion of an approved course is necessary as well. In May 2018 there were in total 1,079 sign language interpreters, 263 trainee sign language interpreters and only 12 registered interpreters for deafblind people (NRCPD, 2018). However, there is no legal obligation to register in order to work as an interpreter, nor is the profession regulated by any other legal means. Therefore, both numbers and qualifications of interpreters may differ. Moreover, there is also a separate register maintained by the Scottish Association of Sign Language Interpreters (SASLI) and the national Association of Sign Language Interpreters (ASLI). The actual interpreter-per-sign-language-user ratio is hard to estimate. However, it seems likely that with about 151,000 BSL users (BDA, 2011), 1,500 ISL (Parks, Parks 2012) and 394,000 deafblind people (https://deafblind.org.uk) in the UK, it would be lowest for the latter ones. Also, available numbers cannot capture a situation where a member of a family or a friend of a hearing-impaired person acts as an interpreter, which is common practice, especially in a medical setting because of greater trust and intimacy of the situation but not necessarily because of sufficient qualifications of the given person.

Even if the organization used to fail to observe obligations imposed by the 2010 Equality Act, starting from 2016 all National Health Service (NHS) providers must follow the Accessible Information Standard. 
The Standard says that patients, service users, carers and parents with a disability, impairment or sensory loss should:

- Be able to contact, and be contacted by, services in accessible ways, for example via email or text message.

- Receive information and correspondence in formats they can read and understand, for example in audio, braille, easy read or large print.

- Be supported by a communication professional at appointments if this is needed to support conversation, for example a British Sign Language interpreter.

- Get support from health and care staff and organizations to communicate, for example to lip-read or use a hearing aid (NHS, 2018).

Unfortunately, the Standard applies only to the health services in England.

The British Deaf Association evaluated the actual impact of the 2010 Equality Act on the rights of sing language users in their everyday life, including health and emergency services. The submission paper (BDA 2015, p. 5) shows that the NHS fails to provide the interpreter, even upon request and in fact family members are being forced to interpret for their deaf relatives. A Sick of It report by the Deaf Health Charity Signhealth (2014) confirms this trend. It revealed that $70 \%$ of deaf people who had a General Practice appointment recently had wanted to go but did not mostly due to the lack of an interpreter. It showed that 8 in 10 deaf people want to communicate using BSL, but only 3 out of 10 get a chance. The 2010 Equality Act makes it a service provider obligation to book and cover costs of an interpreter, but to refrain from it is not a real saving in the long term. As the Sick of It report proved, implementing solutions for better access to health care for the deaf would allow to save up to $£ 30$ million a year. On the other hand, the National Union of British Sign Language Interpreters watches and advocates for fairly standardized fees for interpreters through social campaigns and by delivering fees guidance.

\subsection{Federal Republic of Germany}

In the Federal Republic of Germany, one sign language (German Sign Language, GSL) is distinguished - die Deutsche Gebärdensprache, but it has local modifications or dialects, just like spoken German. A mixed spoken-gesture system of sign-coded German is also used, however, interestingly in contradiction to Sign Supported English its name if translated literally would be: Spoken Language Supported Signs (SSS). Accordingly, classical or contact-GSL or its modifications and other specific means of communication are used by deafblind people.

A spoken Standard German (Hochdeutsch) is not only de facto the official language, but also the language of administration (Amtsprache) and courts (Gerichtssprache) as provided in federal laws. GSL was acknowledged in 2002 as a language in its own right in $\S 6$ of the Disability Equality Act (Gesetz zur Gleichstellung behinderter Menschen) which also states that persons with hearing loss have a right 
to use it. What is more, the scope of this right is specified in a number of other legal instruments. For example, the Regulation on Communication Aid (Коттиnikationshilfenverordnung) provides that it includes a right to communicate in sign language and SSS or using other communication aids with public administration. A person with hearing loss is free to choose a particular form of communication, whichever is suitable. If the sign language interpreter or other communication help provider are appointed, they have a right to compensation from the authority in accordance with rules on compensation and remuneration in the justice system.

Analogical provisions apply to the healthcare system. The second section of $\S 17$ of Social Code I (Sozialegesetzbuch I) provides that persons with hearing disabilities and persons with speech disabilities, while executing social benefits, in particular during medical examinations and treatments, have the right to communicate, in German Sign Language, speech supported signs or other suitable communication aids. The social service providers are obliged to cover the costs of interpretation or other communication aids.

Moreover, the Assistance Regulation concerning illness, care, and birth (Bundesbeihilfeverordnung) grants people with hearing loss the right to have expenses for communication aids covered, where a health care service is medically necessary, in administrative proceedings the right to use a communication aid according to $\S 9$ of the Disability Equality Act, and if it is the only way to ensure information flow between the service provider and the entitled person.

The Integration Office has issued a non-binding recommendation (Empfehlungen zur Bezuschussung I on Kosten für GebärdensprachdolmetscherInnen Leistungen) on subsidies and costs of sign language interpreters.

In Germany, there is a separate profession of official interpreters and translators legitimized to interpret/translate for public purposes. It used to be uncertain if sign language interpreters could acquire such a title. Due to the autonomy of federal states (Länder), the regulation and even the name of the profession is different in each of them; they may be referred to as official interpreters/translators, sworn interpreters/translators and so on. More importantly, the candidates must fulfil different conditions in every state in order to obtain the official title. Taking that into account, it was easier to dispel doubts through federal law. In 2004, a Federal Directive was issued on conducting and recognizing exams for translators, interpreters and sign language interpreters (Richtlinie zur Durchführung und Anerkennung von Prüfungen für Übersetzer/Übersetzerinnen,Dolmetscher/Dolmetscherinnen und Gebaerdensprachdometscher/Gebaerdensprachdolmetscherinen) and so the legal status of GSL and other interpreters/translators has been equalized (without interference in each state's autonomy to decide on the prerequisites of the profession). They are associated in the Federal Association of German Sign Language Interpreters (Bundesverband der GebärdensprachdolmetscherInnen Deutschlands e.V. - BGSD).

According to the EUD, there are 200,000 GSL users and $500 \mathrm{GSL}$ interpreters (2012). But there are great differences in estimated numbers of people with hear- 
ing loss in different sources. For example, the German Deaf Association (Gehörlosen Bund) states that there are about 80,000 deaf people, and even up to 16,000 hard of hearing people and Höcker (2010) reports between 41,000 and 80,000 people with prelingual deafness and about 266,000 people being deaf and hard of hearing in the sense of the provision of the Social Code.

Research by Höcker (2010) also provides detailed information on the practical application of the presented laws by healthcare providers. It showed that the main cause of communication problems and misunderstandings among persons with hearing loss is their unawareness of the right to request an interpreter and that such assistance is free of charge. No problems with costs reimbursements were reported. It was observed that people with higher education tend to have a better awareness of their rights. At the same time, the rate of people with high school level education and above is significantly lower among hearing impaired versus hearing people. Another factor is family dependency common among younger people. "Young, highly family-oriented deaf people should be provided with the knowledge on possible interpreting, in order to enable them to emancipate themselves from their family members in medical matters if they so wish" (Höcker 2010, p. 79). Medical staff, on the other hand, should be instructed that although hearing loss patients willingly accept information in writing, it does not automatically mean that they are able to fully understand it or even read at all. Such practice only shifts the burden of responsibility for the explanation of the so delivered medical information on another person, presumably an unqualified relative (Höcker 2010, p. 72).

Similar conclusions were drawn in the research concerning older deaf people carried out at the University of Cologne (Kaul, Gelhardt, Klinner, Menzel 2009, pp. 79-88). Older people were not only not informed the about possibility of asking for an interpreter, but sometimes doctors even ignored their direct request to speak slowly so they could try lip reading. Also, direct contact seems to be more important for older patients and so they would benefit most if medical staff was trained even in basic sign language competences (Kaul et al. 2009, p. 85).

\subsection{Republic of Poland}

National sign language in the Republic of Poland is the Polish Sign Language (PSL). There is also an artificial Polish Sign-Language System (Polski System Językowo-Migowy) which shares common characteristics with SSE and the SSS as an artificial and subsidiary form of communication between hearing loss and hearing people. Both were acknowledged in the Act of 19 September 2011 on sign language and other means of communication, along with Communication Systems of Deafblind Persons and means of supporting communication (such as text messages or video interpreting). The Act defines PSL as a natural language, however it does not include a general freedom of using it, except for the cir- 
cumstances provided therein, that is in contacts with public administration, state emergency health services, health care entities and police entities, state fire services, municipal services and voluntary units operating in the area (referred to as "obliged entities"). Only spoken Polish is recognized as the official language of the Republic of Poland, as provided in the Constitution and the Act of 7 October 1999 on the Polish language. However, the latter states that Polish is a language of public entities unless otherwise provided. Also, a number of provisions are spread across other legal acts mentioning "deaf or deaf-and-mute" persons, for example notaries are obliged to verify if the deaf or deaf-and-mute person precisely understands the content of the act and they may call an expert for that purpose. Some modifications are also provided as well in court proceedings; in the criminal procedure an interpreter must be called if the deaf person is to be questioned, in civil procedure a testimony can be submitted in writing.

The Act of 19 September 2011 on sign language and other means of communication entitles persons who permanently or temporarily experience difficulties in communicating to freely choose the form of communication when they interact with one of the entities listed above. In case of interpreting, entitled persons have a right to be assisted by the so-called "foster person", that is a person who is at least 16 years of age and was chosen by the entitled person to facilitate communication and assist in settling matters with obliged entities. Foster persons do not have to prove their knowledge of sign language or any other form of communication. Where a foster person is involved in the legal or other action, it is assumed that they operate the given information solely for communication facilitating purposes.

Alternatively, people with hearing loss have a right to receive help from a chosen sign language interpreter or guide-interpreter and the obliged entities are to ensure that such help can be obtained. The more detailed obligations are addressed solely to public administration bodies, including free access to an interpreter. Even then, an entitled person must first obtain a certificate of disability and the statutory remuneration for the interpreter is relatively low. In other situations, including healthcare provision, people who need the help of an interpreter can apply for funding to the National Fund for the Rehabilitation of Disabled Persons. Additionally, it must be noted that it is a doctor's legal obligation to provide information about the patient's state of health in an understandable form.

In Poland, similarly to Germany, there is a separate profession of sworn translators. The difference is that in this case sign language interpreters are explicitly excluded from this profession by the Act of 25 November 2004 on the profession of sworn translators. Instead, the Act of 19 September 2011 provides that there is an official electronic register of sign language, Polish Sign-Language System and Communication Systems of Deafblind Persons interpreters maintained by the voivode, but no gratifications are required to be entered into the register. Also, there are no state examinations or qualifications references. Interestingly, in Poland there is simultaneously in force a Regulation of the Minister of Justice of 
24 January 2005 on court experts, according to which sign language interpreters in judicial proceedings have an expert status and in order to obtain it, they have to be at least 21 years of age and have a T2 Certificate from the Polish Association of the Deaf. Although no legally protected standard of qualifications is ensured, there is an informal Code of Ethics created by the Society of Polish Sign Language Interpreters, which includes declarations on continuous professional development, confidentiality and impartiality. The society also provides a list of its members online and intermediates in booking an interpreter. There is also the Deafblind Assistance Association.

According to the data reported by the Polish Ombudsman (Rzecznik Obywatelski 2014) there are between 50,000-100,000 PSL users and up to 100 PSL interpreters. EUD reports 50,000 PSL users and 200 PSL interpreters. The number of deafblind people is a bit more certain — approximately 2,500 (according to Towarzystwo Pomocy Gluchoniewidomym w Polsce 2016).

In 2016, a report on the implementation of UNCRDPO was released in regard to persons with hearing disability in Poland. The first barrier in access to healthcare is the lack of possibility to book an appointment in any other way than in person or by a telephone call. Secondly, there are problems with reaching emergency health services - the existing text message system is not centralized, and it was not implemented in practice. Respondents complained about very poor knowledge that medical staff has about hearing impairment. They also lacked access to information - not only personal health information, but also a lack of an induction loop in healthcare facilities or other adjustments for navigation. Finally, it is commonly reported that there are few PSL interpreters and those available are often underqualified.

\section{Conclusion}

The presented analysis showed that problems shared by people with hearing loss are similar internationally regardless of the existing (or non-existing) laws. This is mostly due to a very poor social awareness of hearing loss characteristics. Germany is a great example of very thoughtful and effective legal mechanisms, which remain a dead letter because the protected entities are not informed about their existence. Consequently, it seems that there is no direct link between a law and the quality of life of people with hearing loss, at least in access to health care.

A great margin of discretion is left for people with hearing loss to ask their closest ones to interpret during medical examination, which is very questionable. Of course, such people are usually trustworthy and have at least basic competences in signing but it does not automatically mean that they are sufficiently qualified to deliver appropriate medical information or that they even understand the burden of responsibility. It is hard to understand the decision of Polish legis- 
lation to forbid the verification of sign language (or other) competences of foster persons. In each of the analyzed countries more stringent requirements and training should be introduced before admission to medical interpreting.

The question remains, why there are still not enough sign language interpreters. One of the reasons is that sign languages are not universal, and it takes a long time to master them to a level sufficient to handle court or health interpreting. Also, sign language interpreting is not profitable. Sign language interpreters are not forbidden from providing services on the free market, but as the studies showed, due to language barriers in education, people with hearing loss are often less educated and consequently less paid. Therefore, a relatively high demand for interpreting services is not followed by financial possibilities of the clients. This situation leads to a vicious circle where the lack of access to the sign language in one area of life makes it less approachable in the other.

\section{References}

Appiah P.K., Fenu G.A., Asalu G.A., Dzata W.M., Bonchel D.A., Abdul-Rahman T.I., Dongdem Z.A. (2018), "Communication experiences of speech and hearing impaired clients in accessing healthcare in Hohoe municipality of Volta region, Ghana", European Scientific Journal 14, no. 12, pp. 209-228. DOI: http://dx.doi.org/10.19044/esj.2018.v14n12p209.

British Deaf Association (2015), Equality Act 2010 and Disability: Submission Paper to the House of Lords' Select Committee, https://bda.org.uk/wp-content/uploads/BDAOld/40f9d767-09cb495d-a2a8-8a4d16b0db51 (accessed: 10.05.2018).

Chaveiro N., Porto C.C., Barbosa M.A. (2009), "The relation between deaf patients and the doctor", Revista Brasileira de Otorrinolaringologia 75, no. 1, pp. 147-150. DOI: http://dx.doi. org/10.1590/S0034-72992009000100023.

Chininthorn P., Glaser M., Tucker W.D., Diehl J.C. (2016), "Exploration of deaf people's health information sources and techniques for information delivery in Cape Town: A qualitative study for the design and development of a mobile health app", JMIR Human Factors 3, no. 2, e28. DOI: http://doi.org/10.2196/humanfactors.6653.

Deaf Health Charity Signhealth (2014), Sick of It: How the Health Service is Failing Deaf People, https://www.signhealth.org.uk/sick-of-it-report-professionals (accessed: 10.05.2018).

Deuchar M. (2013), British Sign Language, London-New York.

European Commission (2008), Proposal for a Council Directive on implementing the principle of equal treatment between persons irrespective of religion or belief, disability, age or sexual orientation, 2 July 2008, COM(2008) 426 final.

European Commission (2015), Proposal for a Directive of the European Parliament and of the Council on the approximation of the laws, regulations and administrative provisions of the Member States as regards the accessibility requirements for products and services, $\mathrm{COM}(2015) 615$ final.

European Deafblind Network (2014), Mapping Opportunities for Deafblind People across Europe: Government and Voluntary Sector Responses to the Growing Issue of Deafblindness in Europe, http://deafblindindicators.eu/wpcontent/uploads/2016/05/1_1Final-report-Mapping-opportunities_0315.pdf (accessed: 15.05.2018).

European Parliament (2012), Report on eCall: A new 112 service for citizens of 22 June 2012, 2012/2056(INI), http://www.europarl.europa.eu/sides/getDoc.do?pubRef=-//EP//TEXT+RE$\mathrm{PORT}+\mathrm{A} 7-2012-0205+0+\mathrm{DOC}+\mathrm{XML}+\mathrm{V} 0 / / \mathrm{EN}$ (accessed: 15.05.2018).

Ekonomia - Wroclaw Economic Review 24/3 (2018)

(C) for this edition by CNS 
European Parliament (2016), Resolution of 23 November 2016 on sign languages and professional sign language interpreters, http://www.europarl.europa.eu/sides/getDoc.do?pubRef=-//EP// TEXT+TA+P8-TA-2016-0442+0+DOC+XML+V0//EN (accessed: 15.05.2018).

Höcker J.T. (2010), Sozialmedizinische Aspekte der medizinischen Versorgung gehörloser Menschen in Deutschland, Mainz.

Kaul T., Gelhardt A., Klinner A., Menzel F. (2009), Zur Situation gehörloser Menschen im Alter, Köln.

Krakowiak K. (2006), Studia i szkice o wychowaniu dzieci z uszkodzeniami stuchu, Lublin.

Kuenburg A., Fellinger P., Fellinger J. (2016), "Health care access among deaf people", Journal of Deaf Studies and Deaf Education 21, no. 1, pp. 1-10. DOI: https://doi.org/10.1093/deafed/ env042.

Naseribooriabadi T., Sadoughi F., Sheikhtaheri A. (2017), "Barriers and facilitators of health literacy among D/deaf individuals: A review article", Iranian Journal of Public Health 46, no.11, pp. 1465-1474.

National Health Service (2018), Accessible Information Standard: Overview 2017/2018, https://www. england.nhs.uk/wp-content/uploads/2017/10/accessible-info-standard-overview-2017-18.pdf (accessed: 16.05.2018).

National Registers of Communication Professionals working with Deaf and Deafblind People (2018), NRCPD Newsletter May 2018, https://www.nrcpd.org.uk/news.php?article=167, (accessed: 10.05.2018).

Nilsson A., Turner G., Sheikh H., Dean R. (2013), Medisigns: A Prescription for Change: Report on EU Healthcare Provision for Deaf Sign Language Users, https://www.researchgate.net/ publication/260119583_Medisigns_A_prescription_for_change_-_An_overview_of_European_healthcare_provision_for_Deaf_sign_language_users (accessed: 10.05.2018).

Nowacka D. (2016), Raport środowiskowy - środowisko osób z niepetnosprawnościa stuchu. Wdrażanie Konwencji o Prawach Osób Niepetnosprawnych - wspólna sprawa, Warszawa.

Parks E., Parks J. (2012), A Survey Report of the Deaf People of Northern Ireland, SIL International, www.sil.org/resources/publications/entry/43483 (accessed: 5.05.2018).

Rzecznik Praw Obywatelskich (2014), Sytuacja osób g/Gtuchych w Polsce, Warszawa.

Timmermans N. (2005), The Status of Sign Languages in Europe, Strasbourg.

Towarzystwo Pomocy Głuchoniewidomym w Polsce (2016). Gluchoniewidomi w Polsce 2016, Warszawa.

Wheatley M., Pabsch A. (2012), Sign Language Legislation in the European Union, Brussels. 